\title{
A novel NGS-based microsatellite instability (MSI) status classifier with 9 loci for colorectal cancer patients
}

\author{
Kai Zheng ${ }^{1 \dagger}$, Hua Wan ${ }^{2 \dagger}$, Jie Zhang ${ }^{3 \dagger}$, Guangyu Shan ${ }^{2 \dagger}$, Ningning Chai ${ }^{1}$, Dongdong Li ${ }^{2}$, Nan Fang ${ }^{2}$, Lina Liu',

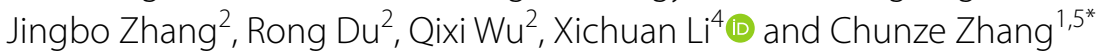

\begin{abstract}
Background: With the recent emergence of immune checkpoint inhibitors, microsatellite instability (MSI) status has become an important biomarker for immune checkpoint blockade therapy. There are growing technical demands for the integration of different genomic alterations profiling including MSI analysis in a single assay for full use of the limited tissues.

Methods: Tumor and paired control samples from 64 patients with primary colorectal cancer were enrolled in this study, including 14 MSI-high (MSI-H) cases and 50 microsatellite stable (MSS) cases determined by MSI-PCR. All the samples were sequenced by a customized NGS panel covering 2.2 MB. A training dataset of 28 samples was used for selection of microsatellite loci and a novel NGS-based MSI status classifier, USCI-msi, was developed. NGS-based MSI status, single nucleotide variant (SNV) and tumor mutation burden (TMB) were detected for all patients. Most of the patients were also independently detected by immunohistochemistry $(\mathrm{IHC})$ staining.
\end{abstract}

Results: A 9-loci model for detecting microsatellite instability was able to correctly predict MSI status with 100\% sensitivity and specificity compared with MSI-PCR, and $84.3 \%$ overall concordance with IHC staining. Mutations in cancer driver genes (APC, TP53, and KRAS) were dispersed in MSI-H and MSS cases, while BRAF p.V600E and frameshifts in TCF7L2 gene occurred only in MSI-H cases. Mismatch repair (MMR)-related genes are highly mutated in MSI-H samples.

Conclusion: We established a new NGS-based MSI classifier, USCI-msi, with as few as 9 microsatellite loci for detecting MSI status in CRC cases. This approach possesses 100\% sensitivity and specificity, and performed robustly in samples with low tumor purity.

Keywords: Microsatellite instability (MSI), NGS, Colorectal cancer (CRC), Immunotherapy, Mismatch repair, TCF7L2, BRAF, KRAS

*Correspondence: chunze.zhang@nankai.edu.cn

${ }^{\dagger}$ Kai Zheng, Hua Wan, Jie Zhang and Guangyu Shan contributed equally to the present article

1 Department of Colorectal Surgery, Tianjin Union Medical Center, Tianjin 300121, China

Full list of author information is available at the end of the article

\section{Background}

Microsatellites, also called short tandem repeats (STRs), are short repeated nucleotide sequences with unit length between 1 and 6 base pairs (bps), which are widely presented in the genome of eukaryotes [1]. Microsatellite instability (MSI) represents the nucleotide insertions or deletions in the microsatellite loci. Alterations in microsatellite regions usually arise during DNA replication. The DNA mismatch repair (MMR) proteins, e.g. MLH1,

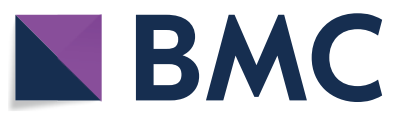

(c) The Author(s) 2020. This article is licensed under a Creative Commons Attribution 4.0 International License, which permits use, sharing, adaptation, distribution and reproduction in any medium or format, as long as you give appropriate credit to the original author(s) and the source, provide a link to the Creative Commons licence, and indicate if changes were made. The images or other third party material in this article are included in the article's Creative Commons licence, unless indicated otherwise in a credit line to the material. If material is not included in the article's Creative Commons licence and your intended use is not permitted by statutory regulation or exceeds the permitted use, you will need to obtain permission directly from the copyright holder. To view a copy of this licence, visit http://creativeco mmons.org/licenses/by/4.0/. The Creative Commons Public Domain Dedication waiver (http://creativecommons.org/publicdomain/ zero/1.0/) applies to the data made available in this article, unless otherwise stated in a credit line to the data. 
MSH2, MSH6 and PMS2, are responsible for the repair of MSI. The germline or somatic inactivation of MMR genes could in turn result in MSI. MSI has been observed in a large number of cancer types, with the highest incidence in colon and endometrial cancers [2, 3]. Germline mutations in MMR proteins are associated with the pathogenesis of Lynch syndrome, which accounts for approximately 20\% MMR-deficient (dMMR) colorectal cancer (CRC) [4]. For sporadic CRC, somatic mutations in microsatellite loci were found in $10 \%$ to $15 \%$ of cases [5].

MSI-H/dMMR cancers are expected to harbor a large number of mutations that might be recognized as neoantigens $[6,7]$ and could enable the patient to be sensitive to immune checkpoint blockade therapies. Thus, MSI status has become an important biomarker for immunotherapy, along with PD-L1 and tumor mutational burden (TMB) [8-11]. Clinical trials have shown that patients with MSI had improved responses to anti-PD-1/PD-L1 drugs, so accurate and efficient determination of MSI status could help to guide clinicians in choosing immuneoncology therapy.

Conventional MSI detection methods include MSIPCR or indirectly by immunohistochemistry (IHC) staining of MMR protein expression. MSI-PCR is performed by amplifying five or more microsatellite loci in tumor and paired normal tissues, and determines MSI status by comparing the repeat number between the paired samples, classified into high (MSI-H), low (MSI-L), and stable (MSS) types. Low tumor purity and serious degradation of DNA may influence the MSI-PCR test. MMR $\mathrm{IHC}$ is a test of evaluating the expression levels of four clinically relevant MMR proteins (MLH1, MSH2, MSH6, and PMS2). dMMR is defined as any of these MMR proteins being totally absent in the nuclear staining of tumor tissue while present in adjacent benign tissue. If all four proteins are present in the tumor tissue, it is considered MMR proficient (pMMR). However, the MMR-related markers included in clinical IHC staining did not cover all MMR relevant genes, which may result in the relatively low correlation between IHC and MSI-PCR.

As Next-Generation Sequencing (NGS) has become a mainstream technology in oncology, NGS-based MSI detection methods are emerging. The selection of microsatellite loci may greatly influence the performance of the MSI detecting tools. According to previous studies, mononucleotide repeats are more sensitive than dinucleotide ones [12, 13]. Additionally, microsatellites with 10-20 bp repeat unit are too long to induce the slippage of DNA polymerase [14]. The bioinformatics tools evaluating MSI include tools directly assessing microsatellite loci in DNA, such as MANTIS [15], mSINGS [16], and MSIsensor [17], while others indirectly assess MSI status by analyzing single nucleotide variants and microindel (e.g., MSIseq and MSIpred) $[18,19]$. Here we used MANTIS, which set the tumor and matched normal tissues data as two vectors. An L1 norm was defined to characterize the degree of stability of every site in the case, and the average of the L1 norm of all sites was used for evaluating the MSI status of the sample. In this study, we developed a novel MSI classifier named USCI-msi based on NGS data with 9 microsatellite loci. The classifier shows $100 \%$ sensitivity and specificity in CRC samples. We also analyzed genomic alterations in MSI-H cases and the correlation between MSI and TMB.

\section{Materials and methods}

\section{Patient and sample preparation}

Sixty-four colorectal tumor and matched normal samples were collected from August 2018 to August 2019 and analyzed following approved by the Institutional Review Board at Tianjin Union Medical Center. Written informed consent forms were obtained from each participant. All methods used in this study were performed in accordance with the relevant guidelines and regulations of the NCCN Clinical Practice Guidelines in Oncology: Colon Cancer (2019.V4).

Tumor samples were fresh or formalin-fixed and paraffin-embedded, while the paired control samples were either tumor-adjacent tissues or peripheral bloods. Genomic DNA of tissue and peripheral blood samples were isolated using QIAamp DNA FFPE Tissue Kit (Qiagen, German) and TIANamp Blood DNA Maxi Kit (TIANGEN, China) according to manufacturer' $\mathrm{s}$ instructions, respectively.

\section{MSI-PCR testing}

MSI-PCR testing was performed using the MSI detection kit (Microread Genetics, China) according to the manufacturer's instructions. The length of PCR fragments were detected on the ABI 3730xl Genetic Analyzer (Applied Biosystems, USA), and analyzed with the GeneMapper software version 4.0 (Applied Biosystems, USA). Samples were considered as MSI- $\mathrm{H}$ when instability was observed in two or more of the six mononucleotide repeat loci (NR-21, BAT-26, NR-27, BAT-25, NR-24, and MONO27), and as MSS when instability in less than two loci was observed.

\section{IHC staining}

IHC staining was assayed with IHC kits (OriGene, USA) for MLH1, MSH2, MSH6 and PMS2 separately, according to the manufacturer's instructions. dMMR was defined when any of these MMR proteins were totally absent in the tumor tissue while presented in adjacent 
benign tissue. Tumor tissues presenting all MMR proteins were defined as PMMR.

\section{Next-generation sequencing}

A custom-designed $2.2 \mathrm{Mb}$ panel, covering exons and partial introns of cancer driver genes, hereditary cancer related genes and therapy-related genes, was used in this study. 50-100 ng of sheared genomic DNAs were subjected to library construction with an MGIEasy universal DNA library kit (MGI, China), then followed by hybrid capture using an xGen Hybridization and Wash Kit (IDT, USA). Libraries' quality and concentration were determined using a LabChip ${ }^{\circledR}$ GX Touch $^{\mathrm{TM}}$ nucleic acid analyzer (PerkinElmer, USA) and a Qubit fluorometer 3.0 (Life Technologies, USA), respectively. Tumor-matched normal samples were also sequenced as controls. The qualified libraries were sequenced with $2 \times 100 \mathrm{bp}$ paired-end reads on a MGISEQ-2000 (MGI, China) platform. The paired-end reads were aligned to human reference genome GRCh37/hg19 using BWA-MEM (v0.7.17) [20] and single nucleotide variants (SNVs) were determined by VarScan (v2.4.3) [21]. TMB was assessed as described by Chalmers and colleagues [14].

\section{Development of USCI-msi}

A novel MSI status classifier, USCI-msi, was developed using a training dataset of 28 samples which included 7 MSI-H and 21 MSS samples determined by gold standard MSI-PCR. Microsatellite loci were first identified across the human reference genome (GRCh37/hg19) by RepeatFinder, and then limited to our panel region. The mononucleotide homopolymers, including the six mononucleotide loci used in the MSI-PCR test, were selected and analyzed in the training dataset with MANTIS using the default setting [15]. Low-quality paired-end reads were filtered out by length $<35 \mathrm{bp}$ and base quality $<25$. Low-quality microsatellite loci were filtered out by average base quality $<30$ and minimum coverage $<30 \times$, repeat type for a microsatellite locus $<3$. The average instability scores for each locus in MSI-H and MSS samples were sorted in descending order. The loci that overlapped among the top 50 loci in the MSI-H cases and the bottom 50 loci in the MSS cases were chosen as marker microsatellite loci and reanalyzed in the training dataset with MANTIS. The NGS-based MSI detection method with the marker microsatellite loci was named USCI-msi classifier, and its performance was then validated with another 36 CRC samples.

\section{Statistical analysis}

The difference between MSS and MSI-H cases were determined by Fisher's exact test or non-parametric Mann-Whitney U test. Two-sided $\mathrm{p}<0.05$ was considered statistically significant.

\section{Results}

\section{Evaluation of MSI status with USCI-msi}

There were 2,952,815 microsatellite loci identified over the genome with repeat region across $10 \mathrm{bp}$ to $100 \mathrm{bp}$ and repeat length across one to five (Fig. 1). 2,263 microsatellite loci were localized in the targeted region of our customized NGS panel. Since mononucleotide microsatellites were shown to be more sensitive in traditional MSI detection scenarios [12, 13], 363 mononucleotide repeat loci were selected for the downstream analysis.
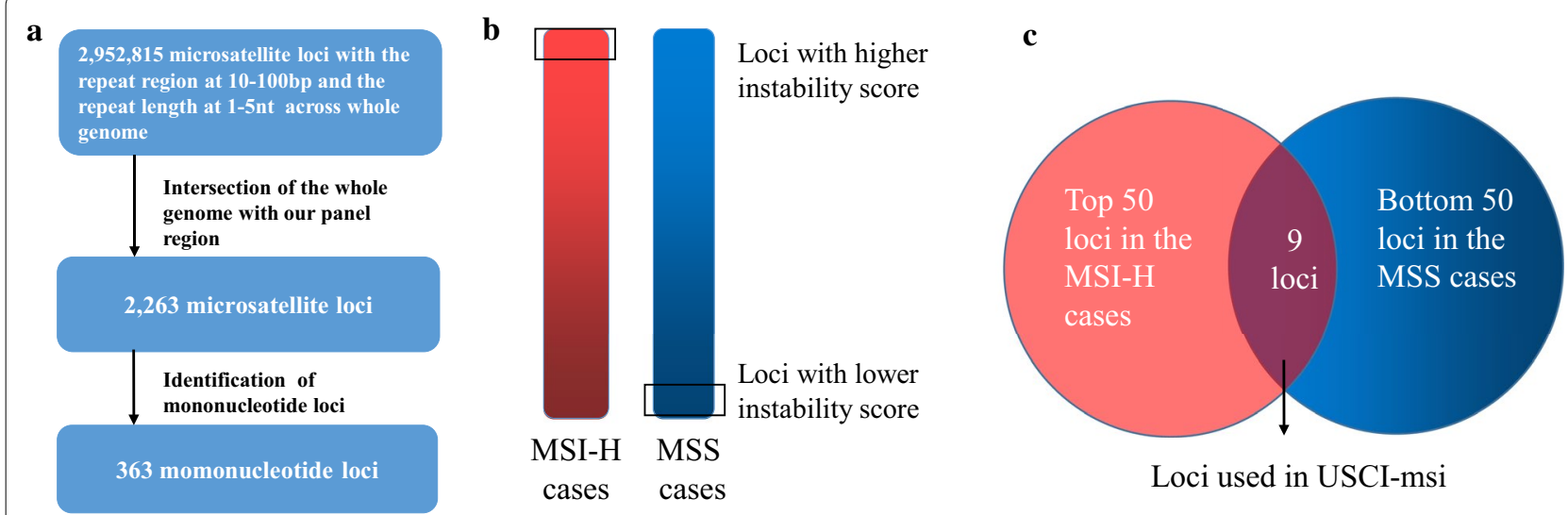

Fig. 1 Schematic illustration of the selection pipeline (a-c) for microsatellite loci. 363 mononucleotide loci in our panel region were selected (a) and used for detecting MSI status. The 363 microsatellite loci were then sorted in descending order by the mean instability score calculated by MANTIS in MSI-H and MSS cases (b). The overlap of the top 50 loci in MSI-H cases and the bottom 50 loci in MSS cases was chosen for training USCI-msi (c) 
We first evaluated the performance of the 363-loci classifier. Among the 28 samples in the training set, which included 7 MSI-H and 21 MSS cases, only one MSI-H sample was misjudged and defined as MSS. Then we analyzed the average instability scores of microsatellite loci in the MSI-H and MSS samples separately, and nine loci were the overlap between the top 50 loci in the MSI-H cases and the bottom 50 loci in the MSS, which may have the strongest discrimination power (Fig. 1). The training set samples were reanalyzed with the nine loci, which reached $100 \%$ accuracy, and then the nine loci MSI detection method was named USCI-msi classifier. The performance of USCI-msi was further evaluated in a CRC validation cohort $(\mathrm{N}=36)$. The mean MSI score of MSI-H samples $(0.78$, range $0.47-0.97)$ was significantly higher than that of MSS samples (0.06, range 0.04-0.10) (Fig. 2a).

\section{A comparison among USCI-msi, MSI-PCR and IHC}

All MSI status recognized by USCI-msi was consistent with those by MSI-PCR. The overall percent agreement (OPA) relative to MSI-PCR was 100\% (64/64) in the combination of training and validation cohorts (Fig. 2b). As for MMR IHC staining, the results of MSI-NGS, MSIPCR and IHC were not fully concordant $(85.2 \%, 46 / 54)$ (Fig. 2b). Two pMMR samples were considered to be MSI-H by NGS and PCR methods. Then a closing inspection of the panel sequencing data of these two samples was made, and alterations of $P O L E / P O L D 1$ were found in both cases (Additional file 1: Table S2). Moreover, one also harbored alterations in three mismatch repair genes MLH1, MSH6, and PMS2 (Additional file 1: Table S2). These indicated MMR deficiency may be caused by alterations in other related genes, or detrimental alterations which may lead to functional loss in MMR proteins, though normal expression may be retained. Six dMMR cases were evaluated as MSS by USCI-msi, though they were all MSH2-deficient. There was no alteration in MLH1, MSH2, MSH6 and PMS2 genes in these six cases, indicating deficiency of MSH2 may be caused by epigenetic inactivation of $\mathrm{MSH} 2$ or other unknown reasons [22]. It may also be an early event, which had no effect on MSI. However, cases which were free of one or more of MLH1, MSH6 and PMS2 proteins were detected as MSI-H.

\section{The correlation of MSI status with patients' clinical characteristics}

The clinical characteristics of all the patients in this study are summarized in Table 1. The mean age of patients with clear information was $60.11 \pm 11.67$, ranging from 32-87. Two $(2 / 57,3.5 \%)$ patients were younger than 40 years, 27 $(27 / 57,47.37 \%)$ patients were between 40 and 60 years, and $28(28 / 57,49.12 \%)$ patients were older than 60 years. Patients with tumor stage I, II, III, and IV accounted for 9.43\% (5/53), 39.62\% (21/53), 49.06\% (26/53) and 1.89\% (1/53), respectively. The incidences of right hemicolon cancer, left hemicolon cancer and rectum cancer were $16 \%(8 / 50), 46 \%(23 / 50)$ and $38 \%(19 / 50)$, respectively. Clinical characteristics associated with MSI status were then examined: Patients aged between 40 and 60 years or with a tumor located at the right hemicolon were more likely to be MSI-H ( $p=0.0174$ and $p=0.0001$, respectively). There was no statistically significant difference between the results for gender and tumor stage in MSI-H and MSS samples.

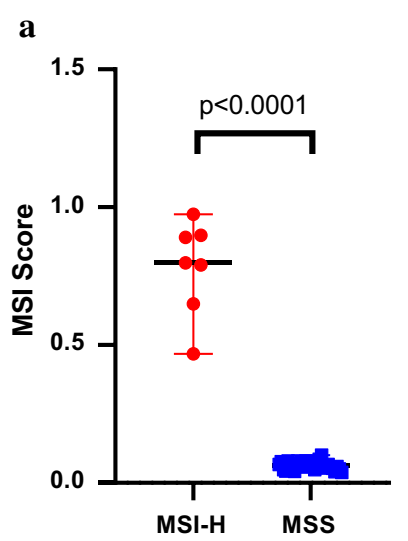

b

\begin{tabular}{|c|c|c|c|c|c|}
\hline & & \multicolumn{2}{|c|}{ PCR } & \multicolumn{2}{|c|}{ IHC } \\
\hline & & MSI-H & MSS & $\mathrm{dMMR}$ & pMMR \\
\hline \multirow{2}{*}{$\begin{array}{c}\text { USCl- } \\
\text { msi }\end{array}$} & MSI-H & 14 & 0 & 7 & 2 \\
\hline & MSS & 0 & 50 & 6 & 39 \\
\hline
\end{tabular}

Fig. 2 The performance of USCI-msi classifier. a USCI-msi was evaluated in the validation cohort ( $\mathrm{N}=36)$. MSI-H and MSS cases were grouped by MSI-PCR. The MSI status recognized by USCI-msi was consistent with those by MSI-PCR at the cutoff of 0.4. The mean MSI score of MSI-H samples (0.78, range $0.47-0.97)$ was significantly higher than that of MSS samples $(0.06$, range $0.04-0.10)(p<0.0001)$. b A comparison among USCI-msi, MSI-PCR and IHC in the combination of training and validation cohorts. All MSI status recognized by USCI-msi were consistent with those by MSI-PCR, though only $85.2 \%(46 / 54)$ with IHC 
Table 1 Characteristics of patients in this study

\begin{tabular}{|c|c|c|c|c|}
\hline & Total $(\mathrm{N}=64)$ & $\begin{array}{l}\text { MSI-H } \\
(\mathrm{N}=14)\end{array}$ & MSS $(\mathrm{N}=50)$ & $p$ value \\
\hline Age & & & & 0.0174 \\
\hline$<40$ & 2 & 0 & 2 & \\
\hline $40-60$ & 27 & 11 & 16 & \\
\hline$>60$ & 28 & 3 & 25 & \\
\hline Missing & 7 & 0 & 7 & \\
\hline Gender & & & & 0.2241 \\
\hline Female & 24 & 8 & 16 & \\
\hline Male & 33 & 6 & 27 & \\
\hline Missing & 7 & 0 & 7 & \\
\hline Clinical stage & & & & 0.2248 \\
\hline 1 & 5 & 0 & 5 & \\
\hline$\|$ & 21 & 6 & 15 & \\
\hline III & 26 & 2 & 24 & \\
\hline IV & 1 & 0 & 1 & \\
\hline Missing & 11 & 6 & 5 & \\
\hline Cancer location & & & & 0.0005 \\
\hline $\begin{array}{l}\text { Right hemi- } \\
\text { colon }\end{array}$ & 8 & 5 & 3 & \\
\hline $\begin{array}{l}\text { Left hemico- } \\
\text { lon }\end{array}$ & 23 & 1 & 22 & \\
\hline Rectum & 19 & 1 & 18 & \\
\hline Missing & 14 & 7 & 7 & \\
\hline
\end{tabular}

MSI-H and MSS were grouped by USCI-msi. Fisher's exact test was used and patients with missing information were removed

MSI-H microsatellite instability-high, MSS microsatellite stability

\section{The performance of USCI-msi classifier on low tumor content samples}

To estimate the performance of the USCI-msi classifier at low sample purity, two MSI-H samples with tumor contents of $32 \%$ and $67 \%$ were selected for gradient dilution experiments. As shown in Table 2, the MSI score correlated with the tumor content along with the dilution with the matched normal tissue DNA. When diluted to $50 \%$, all mixtures were classified as MSI-H, and the sample with the higher score was still confirmed as MSI-H at $33 \%$ dilution. Based on the dilution factor, the MSI classifier is robust to the tumor content as low as $16 \%$.

\section{Genomic alterations across MSI-H tumors}

There were total 2249 alterations across 468 genes in 64 CRC cases. Alterations were significantly enriched in MSI-H samples, with 78\% (1756 alterations in 447 genes) found in 14 MSI-H samples, while 22\% (493 alterations in 186 genes) were found in 50 MSS samples (Fig. 3). The mean number of alterations was 125 (range 63-302) for MSI-H cases, and 10 (range 1-26) for MSS. 60.2\% $(282 / 468)$ of the genes were only affected in MSI-H cases, while only 4.5\% (21/468) in MSS (Fig. 3). At gene level, the top mutated genes only in MSI-H cases included ANKRD11 (78.6\%, 11/14), ARID1A (71.4\%, 10/14), KMT2B (71.4\%, 10/14), BCORL1 (64.3\%, 9/14), IGF1R (50\%, 7/14), KDM5 (50\%, 7/14), POLD1 (50\%, 7/14) and TSC1 (50\%, 7/14) (Additional file 1: Table S2 and Fig. 4). Alterations in the hot genes of CRC, APC, TP53 and $K R A S$, were common in both MSI-H and MSS cases (Additional file 1: Table S2 and Fig. 4).

There were 90 recurrent mutations in 85 genes, of which the most frequent ones were p.E384fs in TCF7L2 (NM_001198530), p.G659fs in RNF43 (NM_017763) and p.E125fs in TGFBR2 (NM_003242) (Table 3). All of these three mutations were located at mononucleotide repeat regions and were detected in 10, 7 and $6 \mathrm{MSI}-\mathrm{H}$ cases, respectively, which indicated that microsatellite loci were commonly unstable in MSI-H cases [23-25]. Hot mutations, p.G12V/S/D/A, p.G13D and p.A146T of KRAS, were found in both MSI-H and MSS cases, while BRAF

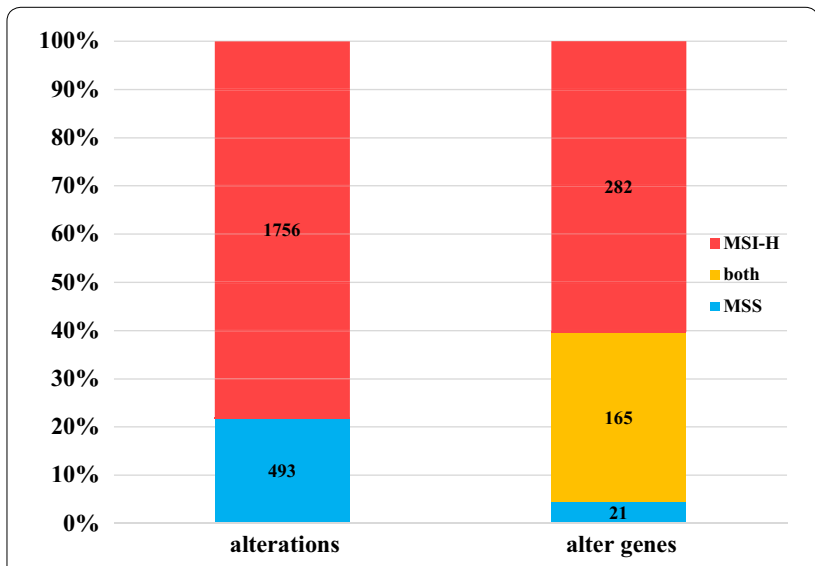

Fig. 3 Schematic illustration of altered sites and genes in 64 colorectal cancer cases
Table 2 Dilution assay

\begin{tabular}{llll}
\hline Dilution, \% & Tumor purity, \% & MSI score & MSI status \\
\hline 100 & 32 & 0.87 & MSI-H \\
50 & 16 & 0.46 & MSI-H \\
33 & 10.6 & 0.26 & MSS \\
20 & 6.4 & 0.20 & MSS \\
100 & 67 & 1.26 & MSI-H \\
50 & 33.5 & 0.67 & MSI-H \\
33 & 22.3 & 0.42 & MSI-H \\
20 & 13.4 & 0.28 & MSS \\
\hline
\end{tabular}

Two MSI-H samples with tumor contents of $32 \%$ and $67 \%$ were selected for gradient dilution experiments by diluting tumor DNAs with their matched normal DNAs. The mixtures were tested for MSI status by USCI-msi

MSI-H microsatellite instability-high, MSS microsatellite stability 


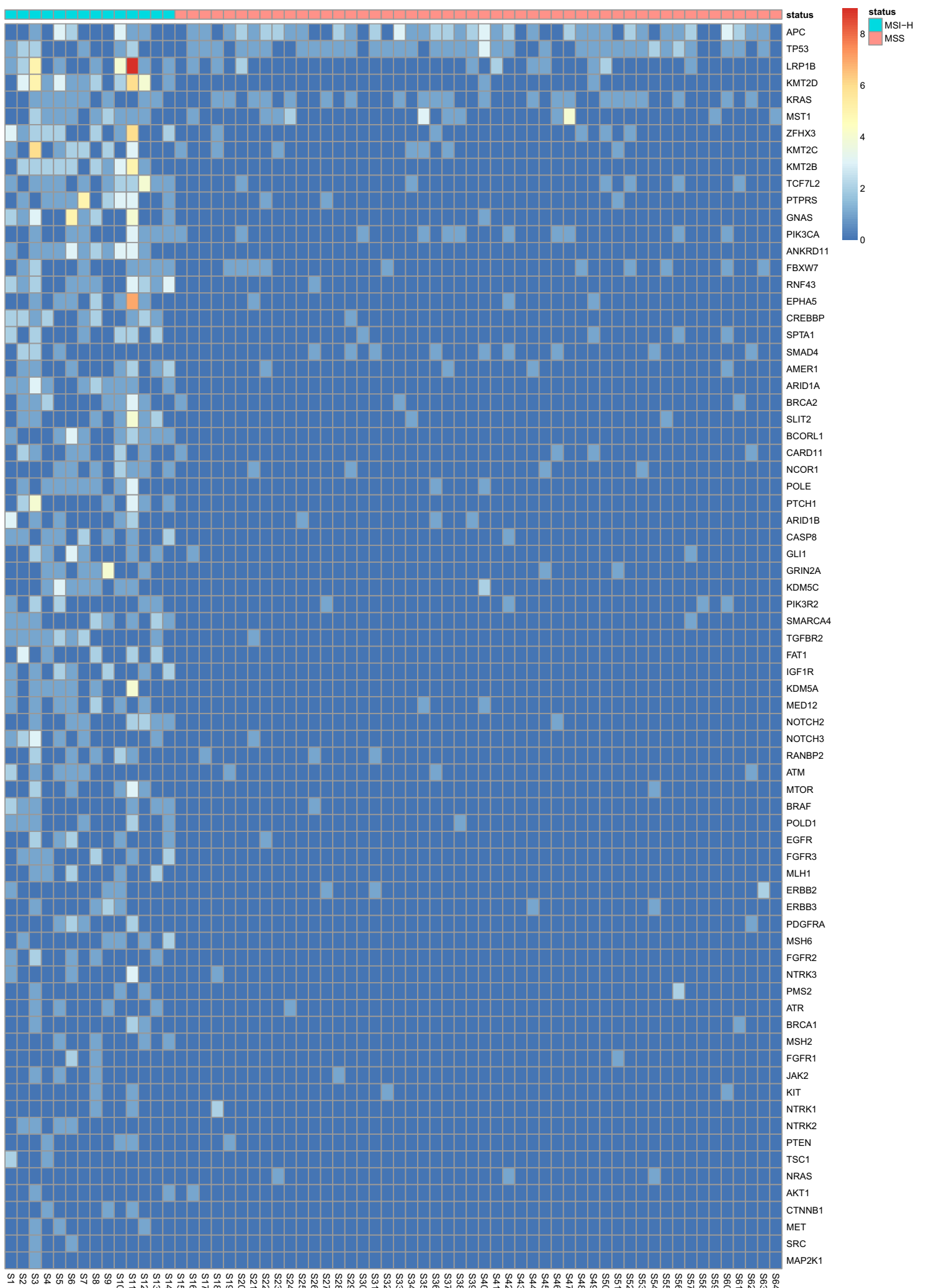

Fig. 4 Hotspot mutant genes in 64 colorectal cancer cases. The most frequent mutant genes are listed in descending order. Colour bar, mutant frequency of genes in a sample 
Table 3 Hotspot mutations in colorectal cancer cases

\begin{tabular}{|c|c|c|c|c|}
\hline \multirow[t]{2}{*}{ Gene } & \multirow[t]{2}{*}{ Hotspot } & \multicolumn{3}{|c|}{ Number of variant cases } \\
\hline & & Total & MSI-H & MSS \\
\hline \multirow[t]{4}{*}{ KRAS } & p.G12V/S/D/A & 16 & 3 & 13 \\
\hline & p.G13D & 7 & 5 & 2 \\
\hline & p.Q61H & 2 & 0 & 2 \\
\hline & p.A146T & 4 & 3 & 1 \\
\hline NRAS & p.Q61R/H/L & 3 & 0 & 3 \\
\hline BRAF & p.V600E & 4 & 4 & 0 \\
\hline TCF7L2 & p.E384fs & 10 & 10 & 0 \\
\hline RNF43 & p.G659fs & 7 & 7 & 0 \\
\hline TGFBR2 & p.E125fs & 6 & 6 & 0 \\
\hline QKI & p.K132fs & 4 & 4 & 0 \\
\hline CARD11 & p.R555fs & 3 & 3 & 0 \\
\hline BCORL1 & p.S1679fs & 3 & 3 & 0 \\
\hline JAK3 & p.Q39fs & 2 & 2 & 0 \\
\hline BCOR & p.Q1156fs & 2 & 2 & 0 \\
\hline
\end{tabular}

p.G12V/S/D/A, p.G13D and p.A146T of KRAS were found in both MSI-H and MSS cases, while BRAF p.V600E was only found in $4 \mathrm{MSI}-\mathrm{H}$ cases. p.E384fs of TCF7L2 were highly mutated in MSI-H samples

fs fragment shift

p.V600E were only found in 4 MSI-H cases (Table 3), which indicated that BRAF p.V600E may be correlated with MSI [26].

Eleven of MSI-H $(78.6 \%, 11 / 14)$ and one of MSS (2\%, $1 / 50$ ) cases carried mutations in the four MMR genes, MLH1, MSH6, MSH2 and PMS2 (Fig. 4). Mutations in these four genes were found in five, five, four and four MSI-H samples, respectively. Four cases were detected with mutations in two or more of these genes. All of above indicated that MMR-related genes were highly mutated in MSI-H samples.

In all the CRC samples, MSI-H tumors had a significantly increased mean TMB (59.65 mutations/Mb) compared to MSS samples (6.15 mutations/Mb) (Fig. 5). The minimal TMB score of MSI-H samples (37.8 mutations/ $\mathrm{Mb}$ ) far outstripped the top TMB score of MSS samples (16 mutations/Mb). Thus, MSI status was also highly correlated with TMB ( $\mathrm{p}<0.0001$, Fig. 5).

\section{Discussion}

With the increasingly routine adoption of clinical NGS panels to oncology, it is crucial to profile different genomic variations by the integration of multiple components in a single assay, which could make full use of the limited tissues and simplify procedures. The panel used in this study covered more than 600 genes, including most cancer-related genes, which was sufficient for genomic profiling across diverse tumor types, including CRC. In this study, we present a novel NGS-based tool,

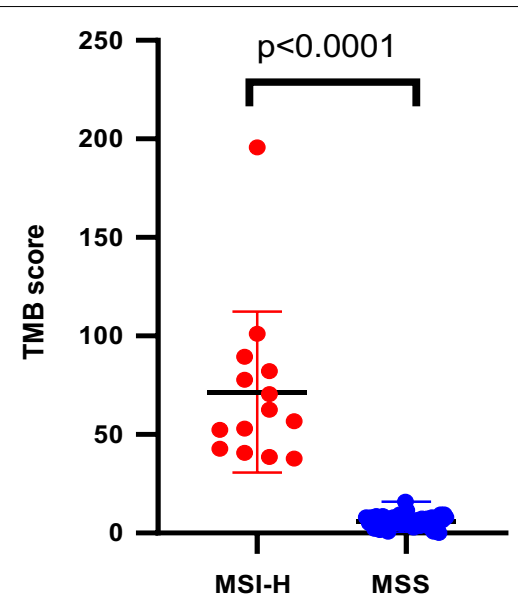

Fig. 5 MSI-H correlated with high TMB in colorectal cancer patients. MSI-H tumors had a significantly increased mean TMB (59.65 mutations/Mb) compared to MSS samples ( 6.15 mutations/Mb) $(p<0.0001)$

USCI-msi, to detect MSI status. This method achieved $100 \%$ sensitivity and $100 \%$ specificity in CRC samples, which is comparable to or better than the recent reports [27-30]. Pang et al. developed a decision tree classifier model and was able to correctly predict the MSI status of 112 clinical cases with $100 \%$ sensitivity and specificity using 8682 mononucleotide and dinucleotide repeat loci [27]. A PCA method was used to generate an MSI score for stratification of MSI-H and MSS patients from a NGS comprehensive genomic profiling assay (FoundationOne and FoundationOneHeme panel). The sensitivity of this method was $97.0 \%$ when compared to corresponding MSI-PCR and IHC [28]. In a cohort with 2189 matched cases, the MSI-NGS method with 7317 target microsatellite loci had a sensitivity of $95.8 \%$, specificity of $99.4 \%$, positive predictive value of $94.5 \%$, and negative predictive value of $99.2 \%$ as compared to MSI-PCR [29]. These methods based on target capture sequencing included most of the microsatellite loci in the target region. Gallon et al. presented a single molecule molecular inversion probe and sequencing-based MSI assay with six loci and achieved $100 \%$ concordance with the MSI-PCR in 220 CRCs [30]. However microsatellite loci selection of this modified amplicon sequencing method was limited to a small amount of candidate loci. USCI-msi with nine microsatellite loci, accompanied genomic profiling assay, showed a better performance than the unselected 363loci set. Some of the genes covering the 9 loci have been previously reported frequently mutated in MSI-H tumors (e.g., microsatellites in POLD1, EP300) [27, 31]. The six mononucleotide repeat sequences used in MSI-PCR were also included in the 363-loci classifier, but were 
absent in the final classifier. Our data also proved that fewer than 10 loci were sufficient to classify MSI status in CRC cases, but the selection of the loci should adjust to the NGS panel used.

We also analyzed alterations in our Chinese cohort. There were many more alterations in MSI-H cases than in MSS cases, though cancer driver genes such as $A P C$, TP53, and KRAS are commonly mutated in CRC samples, regardless the MSI status. The most frequent mutation in MSI-H cases was TCF7L2 p.E384fs. Frameshift mutations in TCF7L2 gene had been found in colorectal and gastric carcinomas with high MSI [23, 24]. TCF7L2 is an important member in the Wnt signaling pathway and mutations in Wnt-related genes were also found to be enriched in MSI-H cases in a cohort of 67,000 pantumor cases [28]. The mismatch repair genes were highly mutated in MSI-H samples, which indicated MSI was a result of MMR gene dysfunction. However, the relatively low concordance between USCI-msi and IHC confirmed that loss of MSH2 protein didn't always result in MSI.

MSI has become a promising biomarker for predicting therapeutic response to immune checkpoint inhibitors. Recently, pembrolizumab was approved for all types of solid tumors exhibiting MSI-H. Consistent with previous studies, MSI-H cases had higher TMBs than the MSS cases in our study. Metastatic colorectal cancer with high MSI has a good response to immunological checkpoint inhibitor therapies [8-11]. Tumors with high MSI may contain abundant new antigens that can elicit an immune response; thus, determining MSI status offers an opportunity to identify patients who may benefit from immunotherapy. In this study, USCI-msi classifier was only tested in CRC cases. In the future, it will be evaluated on more cancer types.

\section{Conclusion}

We described a new NGS-based MSI classifier, USCImsi, with as few as 9 microsatellite loci for detecting MSI status in CRC cases. This approach possesses $100 \%$ sensitivity and specificity, and performed robustly in samples with low tumor purity.

\section{Supplementary information}

Supplementary information accompanies this paper at https://doi. org/10.1186/s12967-020-02373-1.

Additional file 1: Table S1. Alterations in two pMMR samples which were considered MSI-H by USCI-msi. Table S2. Gene enrichment in MSI-H or MSS cases. Genes with ten or more alterations in the colorectal cancer cases are listed. Genes with alterations only in MSI-H cases are in bold.

\section{Abbreviations}

CRC: Colorectal cancer; MSI: Microsatellite instability; MSI-H: MSI-high; MSI-L: MSI-low; MSS: Microsatellite stability/stable; IHC: Immunohistochemistry;
pMMR: Mismatch repair (MMR) proficient; dMMR: MMR-deficient; STRs: Short tandem repeats; SNV: Single nucleotide variant; TMB: Tumor mutational burden.

\section{Acknowledgements}

We thank all patients for consenting to participate. We are grateful to Mr. Yunchao Liu, Mr. Dongxing Zhang, Mr. Qiang Zhang and Ms. Juan Zhang for their helps in this study. We thank all the reviewers and editors for their suggestions on this manuscript.

\section{Authors' contributions}

CZZ, QXW and XCL designed the study. KZ, JZ recruited patients in the clinical study for this analysis. XCL, JZ, and HW performed the laboratory experiments. CZZ, NNC, LNL, HW, GYS collected and assembled the data. CZZ, XCL, HW, GYS, $D D L, N F, J B Z, R D$ analyzed and interpreted the data. HW wrote the manuscript. QXW edited the manuscript. KZ revised the manuscript. All authors read and approved the final manuscript.

\section{Funding}

This work was supported by the Tianjin Health and Family Planning Commission Grant (2017057 to Chunze Zhang), the Open Research Foundation of State Key Laboratory of Medicinal Chemical Biology NanKai University (2018094 to Chunze Zhang), the Key Technologies R \& D Program of Tianjin (Grant 19YFZCSY00420 to Chunze Zhang and 18JCYBJC28100 to Xichuan Li), the National Natural Science Foundation of China (Grant 81872236 to Xichuan $\mathrm{Li}$ ), and the Foundation of Tianjin Medical University Cancer Institute and Hospital (1707 to Jie Zhang).

\section{Availability of data and materials}

The datasets used during the current study are available from the corresponding author on reasonable request.

\section{Ethics approval and consent to participate}

This study was approved by the Ethics Committee of Tianjin Union Medical Center. Written informed consent was obtained from the patients for publication of this manuscript and any accompanying images.

\section{Consent for publication}

Not applicable.

\section{Competing interests}

GYS, DDL, JBZ and QXW are named as inventors on a patent filed by their employer Beijing USCI Medical Laboratory covering the marker set described in this paper (Patent ID: 201911330965.6, unpublished, filing date 12th Dec 2019). HW, GYS, DDL, NF, JBZ, RD and QXW receive salary in Beijing USCI Medical Laboratory Co., Ltd. The other authors declare that they have no competing interests.

\section{Author details}

${ }^{1}$ Department of Colorectal Surgery, Tianjin Union Medical Center, Tianjin 300121, China. ${ }^{2}$ Beijing USCI Medical Laboratory, Beijing 100195, China. ${ }^{3}$ Department of Breast Oncology, Tianjin Medical University Cancer Institute and Hospital, National Clinical Research Center for Cancer, Tianjin's Clinical Research Center for Cancer, Key Laboratory of Cancer Prevention and Therapy, Tianjin Medical University, Tianjin 300060, China. ${ }^{4}$ Tianjin Key Laboratory of Animal and Plant Resistance, College of Life Sciences, Tianjin Normal University, Tianjin 300387, China. ${ }^{5}$ State Key Laboratory of Medicinal Chemical Biology, Nankai University, Tianjin 300070, China.

Received: 22 January 2020 Accepted: 12 May 2020

Published online: 28 May 2020

\section{References}

1. Kelkar YD, Strubczewski N, Hile SE, Chiaromonte F, Eckert KA, Makova KD. What is a microsatellite: a computational and experimental definition based upon repeat mutational behavior at A/T and GT/AC repeats. Genome Biol Evol. 2010;2:620-35. 
2. Hause RJ, Pritchard CC, Shendure J, Salipante SJ. Classification and characterization of microsatellite instability across 18 cancer types. Nat Med. 2016;22:1342-50

3. Le DT, Durham JN, Smith KN, Wang H, Bartlett BR, Aulakh LK, Lu S, Kemberling H, Wilt C, Luber BS, et al. Mismatch repair deficiency predicts response of solid tumors to PD-1 blockade. Science. 2017;357:409-13.

4. Hampel H, Frankel WL, Martin E, Arnold M, Khanduja K, Kuebler P, Clendenning $M$, Sotamaa K, Prior T, Westman JA, et al. Feasibility of screening for Lynch syndrome among patients with colorectal cancer. J Clin Oncol. 2008;26:5783-8

5. Pino MS, Chung DC. Microsatellite instability in the management of colorectal cancer. Expert Rev Gastroenterol Hepatol. 2011;5:385-99.

6. Smyrk TC, Watson P, Kaul K, Lynch HT. Tumor-infiltrating lymphocytes are a marker for microsatellite instability in colorectal carcinoma. Cancer. 2001;91:2417-22.

7. Dolcetti R, Viel A, Doglioni C, Russo A, Guidoboni M, Capozzi E, Vecchiato N, Macri E, Fornasarig M, Boiocchi M. High prevalence of activated intraepithelial cytotoxic T lymphocytes and increased neoplastic cell apoptosis in colorectal carcinomas with microsatellite instability. Am J Pathol. 1999:154:1805-13.

8. Le DT, Uram JN, Wang H, Bartlett BR, Kemberling H, Eyring AD, Skora $A D$, Luber BS, Azad NS, Laheru D, et al. PD-1 blockade in tumors with mismatch-repair deficiency. N Engl J Med. 2015;372:2509-20.

9. Kim JH, Park HE, Cho NY, Lee HS, Kang GH. Characterisation of PD-L1-positive subsets of microsatellite-unstable colorectal cancers. Br J Cancer. 2016;115:490-6.

10. Dudley JC, Lin MT, Le DT, Eshleman JR. Microsatellite instability as a biomarker for PD-1 blockade. Clin Cancer Res. 2016;22:813-20.

11. Llosa NJ, Cruise M, Tam A, Wicks EC, Hechenbleikner EM, Taube JM, Blosser RL, Fan H, Wang H, Luber BS, et al. The vigorous immune microenvironment of microsatellite instable colon cancer is balanced by multiple counter-inhibitory checkpoints. Cancer Discov. 2014;5:43-51.

12. Dietmaier W, Wallinger S, Bocker T, Kullmann F, Fishel R, Ruschoff J. Diagnostic microsatellite instability: definition and correlation with mismatch repair protein expression. Cancer Res. 1997;57:4749-56.

13. Umar A, Boland CR, Terdiman JP, Syngal S, de la Chapelle A, Ruschoff J, Fishel R, Lindor NM, Burgart LJ, Hamelin R, et al. Revised Bethesda Guidelines for hereditary nonpolyposis colorectal cancer (Lynch syndrome) and microsatellite instability. J Natl Cancer Inst. 2004;96:261-8.

14. Chalmers ZR, Connelly CF, Fabrizio D, Gay L, Ali SM, Ennis R, Schrock A, Campbell B, Shlien A, Chmielecki J, et al. Analysis of 100,000 human cancer genomes reveals the landscape of tumor mutational burden. Genome Med. 2017;9:34.

15. Kautto EA, Bonneville R, Miya J, Yu L, Krook MA, Reeser JW, Roychowdhury S. Performance evaluation for rapid detection of pan-cancer microsatellite instability with MANTIS. Oncotarget. 2017;8:7452-63.

16. Salipante SJ, Scroggins SM, Hampel HL, Turner EH, Pritchard CC. Microsatellite instability detection by next generation sequencing. Clin Chem. 2014;60:1192-9.

17. Niu B, Ye K, Zhang Q, Lu C, Xie M, McLellan MD, Wendl MC, Ding L. MSIsensor: microsatellite instability detection using paired tumor-normal sequence data. Bioinformatics. 2013;30:1015-6.

18. Huang MN, McPherson JR, Cutcutache I, Teh BT, Tan P, Rozen SG. MSIseq: software for assessing microsatellite instability from catalogs of somatic mutations. Sci Rep. 2015;5:13321.
19. Wang C, Liang C. MSIpred: a python package for tumor microsatellite instability classification from tumor mutation annotation data using a support vector machine. Sci Rep. 2018;8:17546.

20. Li H. Aligning sequence reads, clone sequences and assembly contigs with BWA-MEM. ArXiv. 2013;2013:1303.

21. Koboldt DC, Zhang Q, Larson DE, Shen D, McLellan MD, Lin L, Miller CA, Mardis ER, Ding L, Wilson RK. VarScan 2: somatic mutation and copy number alteration discovery in cancer by exome sequencing. Genome Res. 2012;22:568-76.

22. Ligtenberg MJ, Kuiper RP, Chan TL, Goossens M, Hebeda KM, Voorendt M, Lee TY, Bodmer D, Hoenselaar E, Hendriks-Cornelissen SJ, et al. Heritable somatic methylation and inactivation of $\mathrm{MSH} 2$ in families with Lynch syndrome due to deletion of the $3^{\prime}$ exons of TACSTD1. Nat Genet. 2009:41:112-7.

23. Duval A, Gayet J, Zhou XP, lacopetta B, Thomas G, Hamelin R. Frequent frameshift mutations of the TCF-4 gene in colorectal cancers with microsatellite instability. Cancer Res. 1999;59:4213-5.

24. Kim MS, Kim SS, Ahn CH, Yoo NJ, Lee SH. Frameshift mutations of Wnt pathway genes AXIN2 and TCF7L2 in gastric carcinomas with high microsatellite instability. Hum Pathol. 2009;40:58-64.

25. Jo YS, Kim MS, Lee JH, Lee SH, An CH, Yoo NJ. Frequent frameshift mutations in 2 mononucleotide repeats of RNF43 gene and its regional heterogeneity in gastric and colorectal cancers. Hum Pathol. 2015;46:1640-6.

26. Lin CC, Lin JK, Lin TC, Chen WS, Yang SH, Wang HS, Lan YT, Jiang JK, Yang MH, Chang SC. The prognostic role of microsatellite instability, codon-specific KRAS, and BRAF mutations in colon cancer. I Surg Oncol. 2014;110:451-7.

27. Pang J, Gindin T, Mansukhani M, Fernandes H, Hsiao S. Microsatellite instability detection using a large next-generation sequencing cancer panel across diverse tumour types. J Clin Pathol. 2020;73(2):83-9.

28. Trabucco SE, Gowen K, Maund SL, Sanford E, Fabrizio DA, Hall MJ, Yakirevich E, Gregg JP, Stephens PJ, Frampton GM, et al. A Novel Next-generation sequencing approach to detecting microsatellite instability and pantumor characterization of 1000 microsatellite instability-high cases in 67,000 patient samples. J Mol Diagn. 2019;21:1053-66.

29. Vanderwalde A, Spetzler D, Xiao N, Gatalica Z, Marshall J. Microsatellite instability status determined by next-generation sequencing and compared with PD-L1 and tumor mutational burden in 11,348 patients. Cancer Med. 2018;7:746-56.

30. Gallon R, Sheth H, Hayes C, Redford L, Alhilal G, O'Brien O, Spiewak H, Waltham A, McAnulty C, Izuogu OG, et al. Sequencing-based microsatellite instability testing using as few as six markers for high-throughput clinical diagnostics. Hum Mutat. 2020;41(1):332-41.

31. Cortes-Ciriano I, Lee S, Park WY, Kim TM, Park PJ. A molecular portrait of microsatellite instability across multiple cancers. Nat Commun. 2017:8:15180.

\section{Publisher's Note}

Springer Nature remains neutral with regard to jurisdictional claims in published maps and institutional affiliations.

Ready to submit your research? Choose BMC and benefit from:

- fast, convenient online submission

- thorough peer review by experienced researchers in your field

- rapid publication on acceptance

- support for research data, including large and complex data types

- gold Open Access which fosters wider collaboration and increased citations

- maximum visibility for your research: over $100 \mathrm{M}$ website views per year

At BMC, research is always in progress.

Learn more biomedcentral.com/submissions 